\title{
Dinâmica de Relacionamento e Prováveis Respostas Estratégicas de Programas Brasileiros de Pós-Graduação em Administração à Avaliação da Capes: Proposições Institucionais a partir da Análise de Redes de Co-Autorias
}

\author{
Relationship Dynamics and Probable Strategic Answers of Brazilian Post Graduate \\ Programs in Administration to the Capes Evaluation: Institutional Propositions starting \\ from the Analysis of Co-Authorship Networks.
}

Cristiane Marques de Mello* Doutoranda em Administração pela Universidade Positivo.

João Marcelo Crubellate Doutor em Administração pela Fundação Getúlio Vargas. Professor da Universidade Estadual de Maringá, Maringá/PR, Brasil.

Luciano Rossoni Doutor em Administração pela Universidade Federal do Paraná. Professor da Universidade Positivo, Curitiba/PR, Brasil.

* Endereço: Cristiane Marques de Mello

Universidade Positivo, Rua Prof. Pedro Viriato Parigot de Souza, 5300, Campo Comprido, Curitiba/PR, 81280330. Email: mellcris@gmail.com

Copyright (C) 2010 RAC. Todos os direitos, inclusive de tradução, são reservados. É permitido citar parte de artigos sem autorização prévia desde que seja identificada a fonte. 


\title{
RESUMO
}

O presente trabalho tem como objetivo descrever e analisar as mudanças ocorridas na configuração estrutural das redes de co-autorias entre professores vinculados a Programas Brasileiros de Pós-Graduação (stricto sensu) em Administração e formular proposições, com base na teoria institucional, a respeito das prováveis respostas estratégicas de tais programas à avaliação da Capes. Adotou-se um recorte longitudinal que abrange um período de seis anos, subdivididos em dois triênios: 2001-2003 e 2004-2006. A população pesquisada compreendeu 32 programas de pós-graduação, que foram avaliados pela Capes em 2001, assim como seus 703 pesquisadores identificados. Os dados foram coletados tendo como base o curriculum Lattes dos professores atuantes naqueles programas e foram analisados por meio de rotinas disponibilizadas pelos softwares Ucinet 6.0 e Pajek 1.10. Os resultados apontam aumento na cooperação de co-autoria de um triênio para outro, o que parece indicar aumento da aquiescência dos programas em relação às exigências do órgão de avaliação. As interações tanto podem rejeitar como reforçar pressões institucionais coercitivas e normativas advindas da Capes, quanto à definição das normas que orientam a avaliação trienal dos programas de pós-graduação stricto sensu no Brasil.

Palavras-chave: respostas estratégicas; teoria institucional; redes de co-autorias; pós-graduação; avaliação da Capes.

\begin{abstract}
The aim of this study is to describe and analyze the changes that have taken place in the structural configuration of the co-authorship networks among professors linked to national programs of post graduate (stricto sensu) in Administration and to formulate propositions, based on the institutional theory, regarding the probable strategic answers of such programs to the CAPES evaluation. A longitudinal cutting was adopted encompassing a six-year period, subdivided into two triennials: 2001-2003 and 2004-2006. The researched population includes 32 postgraduate programs that were evaluated by the Capes in 2001, as well as their 703 identified researchers. The data were collected based on the Lattes curriculum of professors who were active in those programs and were analyzed through routines made available by the the Ucinet 6.0 and Pajek 1.10 softwares. The results show an increase in co-operation through co-authorship from one triennial to the other, which would appear to indicate increased consent of the programs in relation to the requirements of the evaluating agency. These interactions may both reject or heighten coercive and normative institutional pressures on the part of the CAPES concerning the definition of the norms that serve as guidelines for the three-yearly evaluation of stricto sensu post-graduate programs in Brazil.
\end{abstract}

Key-words: strategic answers; institutional theory; co-authorship networks; post graduation; Capes evaluation. 


\section{INTRODUÇÃO}

Entre as organizações formais, as universidades são consideradas como uma das mais relevantes para o estudo da influência da dimensão social na ação (Bidwell, 2006; Blau, 1970), diante de sua forte dependência do ambiente institucional (Meyer \& Rowan, 1977). Universidades necessitam especialmente de aprovação pública para legitimar as mudanças em sua estrutura (Alperstedt, Martignago, \& Fiates, 2006). Diante de tal fato, mais do que eficientes, elas precisam ser vistas como socialmente necessárias para sobreviverem.

Não é por acaso que tais organizações, sejam públicas sejam privadas, se deparam com influências que vão além de sua esfera operacional. Por serem as instituições mais relevantes para o desenvolvimento intelectual formal dentro da sociedade contemporânea, universidades são controladas por governos nacionais, ou por suas autarquias, que lhes impõem formas de conduta acerca de sua função na sociedade. Diante dessas pressões e do aumento da complexidade da função acadêmica na modernidade, as universidades tendem a diferenciar e especializar suas atividades. Entre essas, uma das mais fundamentais é a atividade de pesquisa, formalizada nessas organizações por meio dos programas de pós-graduação.

Como função legítima e socialmente reconhecida, a atividade de pesquisa e ensino, desenvolvida pelos programas de pós-graduação, a exemplo de outras atividades ligadas à formação acadêmica, recebem forte condicionamento legal e burocrático, havendo em alguns países corpo especializado para exercer tal função. Esse é o caso da pós-graduação no Brasil, cuja atividade de avaliação dos programas fica a cargo de um órgão especializado do Ministério da Educação: a Coordenação de Aperfeiçoamento de Pessoal de Nível Superior [Capes].

No Brasil, a Capes investe no desenvolvimento da pós-graduação stricto sensu e na qualificação de pessoal no país e também no exterior. A Capes avalia trienalmente cursos de mestrado e doutorado em todos os Estados da Federação e financia a produção e a cooperação científica. Além disso, também é responsável pela concessão de mais de quarenta por cento das bolsas de pós-graduação concedidas a estudantes brasileiros (Conselho Nacional de Desenvolvimento Científico e Tecnológico [CNPq], 2009; GeoCapes, 2009). A Avaliação da Capes inclui dois processos: (1) a avaliação dos programas de pós-graduação integrantes do Sistema Nacional de Pós-Graduação [SNPG]; e (2) a avaliação das propostas de novos cursos de mestrado e doutorado. O Sistema de Avaliação da Pós-graduação foi implantado pela Capes em 1976 e tem sido de fundamental importância para o desenvolvimento e aperfeiçoamento da pós-graduação e da pesquisa científica e tecnológica no país (Nicolato, 2005).

Os programas brasileiros de pós-graduação podem responder de diferentes formas ao sistema de avaliação da Capes. Diante de tal possibilidade, propõe-se, no presente estudo, descrever e analisar as respostas de programas brasileiros de mestrado e doutorado em Administração, que já existiam em 2001 ou em anos anteriores, utilizando como referencial a tipologia de Oliver (1991). Essas respostas são denominadas, aqui, de respostas estratégicas, que podem ir desde a concordância até a rejeição dos critérios adotados pela Capes para avaliação dos programas. No entanto, diferentemente de outros estudos que avaliaram empiricamente tais respostas (por exemplo, Machado-da-Silva, 2003), apontaremos como elas são condicionadas pelos seus relacionamentos. As respostas de uma organização ao ambiente institucional, de acordo com Oliver (1991), influenciarão não somente o desempenho organizacional, como também poderão influenciar os critérios, as medidas, ou os padrões usados por constituintes institucionais para avaliar o desempenho das organizações.

O presente trabalho tem como objetivo descrever e analisar a dinâmica de relacionamento (mudanças ocorridas na configuração estrutural) das redes de co-autorias entre professores vinculados a Programas de Pós-Graduação (stricto sensu) em Administração no Brasil e elaborar proposições, com base na teoria institucional, a respeito das prováveis respostas estratégicas de tais programas à avaliação da Capes nos triênios de 2001-2003 e 2004-2006, a partir da análise de redes. A elaboração das proposições está baseada na tipologia de Oliver (1991), bem como nas especificidades derivadas 
da análise de redes e no suporte teórico da teoria institucional em organizações. Tais proposições têm, certamente, o caráter precário, natural a qualquer esforço de conhecimento a priori da realidade empírica; elas cumprem, entretanto, o papel de orientação de investigações posteriores que, detendo-se sobre a mesma problemática, tenham como objetivo ir além da simples descrição das respostas estratégicas, que se interpretam à luz de alguma teoria ou, especificamente, das teorias que aqui nos dão suporte.

Este estudo pressupõe que a configuração da rede de co-autorias, formada entre os professores vinculados aos programas pesquisados, pode oferecer indicativos das respostas à avaliação da Capes oferecidas por tais programas no período mencionado anteriormente. Considera-se ainda que atores que pertencem ao mesmo campo estão propensos a aceitar e a aderir às mesmas crenças e compartilhar de significados comuns, o que pode condicionar suas ações (Scott, 2001), e sugerir que programas que interagem entre si, por meio de co-autorias entre os professores, tendem a responder de modo semelhante. Esta pesquisa pretende sugerir, a partir da análise de redes, a formulação de proposições institucionais das possíveis respostas estratégicas empreendidas pelos programas de pós-graduação. Por meio da análise de redes é possível a compreensão de aspectos estruturais e dinâmicas de relacionamento entre atores sociais, elementos considerados de fundamental importância para a compreensão dos processos de imersão social e de práticas institucionais. Entender as relações sociais dos atores, no caso considerado, os professores e os programas, pode contribuir para a compreensão da parte do que ocorre na produção científica em administração e na pós-graduação em administração no Brasil, bem como das relações que se estabelecem entre essas organizações e seu ambiente.

Embora haja no Brasil o desenvolvimento de estudos sobre co-autorias (vide, por exemplo, trabalhos de Rossoni, 2006; Rossoni \& Guarido Filho, 2007; Rossoni, Hocayen-da-Silva, \& Ferreira Júnior, 2008) e publicações sobre respostas estratégicas de programas brasileiros de pós-graduação em administração à avaliação da Capes (vide, por exemplo, Machado-da-Silva, 2003), este estudo tem seu foco na possível relação entre esses dois elementos (redes de co-autorias e respostas estratégicas).

O artigo está estruturado em cinco partes, sendo a primeira a introdução. Na sequência será apresentado o quadro teórico que fundamenta a presente pesquisa. A terceira parte é composta pelos procedimentos metodológicos que oferecem sustentação aos dados empíricos. A quarta parte é composta pela apresentação e análise dos resultados relativos às redes e às proposições institucionais e, por fim, as conclusões do estudo.

\section{QUADRO TEÓRICO DE REFERÊNCIA: RESPOSTAS ESTRATÉGICAS E IMERSÃo EM REDES SOCIAIS}

No ambiente universitário brasileiro, as pressões institucionais do governo são consideradas pelos seus dirigentes como decisivas; teorias que não consideram os órgãos governamentais, nem a comunidade como forças ambientais relevantes, possuem pouco poder explicativo (Alperstedt et al., 2006) da relação entre organização e forças ambientais. Tais forças devem ser consideradas especialmente no momento da formulação e implementação das estratégias organizacionais.

A visão institucionalista de estratégia leva em consideração elementos ambientais, culturais, cognitivos e sistêmicos para compreender o processo da formação da estratégia (Crubellate, Grave, \& Mendes, 2004). Essa perspectiva pressupõe o desenho organizacional como processo provindo de pressões externas e internas que, ao longo do tempo, levam as organizações a se tornarem semelhantes. Assim, as escolhas estratégicas seriam determinadas em um contexto institucional no qual uma organização está imersa (Rossetto \& Rossetto, 2005). Para a compreensão das ações organizacionais, Crubellate (2007) defende que a análise institucional e os estudos de estratégia nas organizações necessitam ser analisados nas suas interações, e não de modo dicotômico.

A estrutura institucional pode acomodar uma variedade de respostas estratégicas ao ambiente institucional. Este pressuposto fornece base apropriada de comparação, revelando suposições da teoria 
institucional, identificando um repertório de estratégias alternativas disponíveis às organizações que confrontam demandas e expectativas institucionais e determinam os fatores que predizem quando as organizações resistirão ou se conformarão às pressões institucionais (Oliver, 1991). As escolhas estratégias são feitas mediante as interpretações que os atores dirigentes fazem das pressões provindas dos ambientes (Cochia \& Machado-da-Silva, 2004). Entretanto, as estratégias consideradas formais ou declaradas pelas organizações podem ser vistas apenas como instrumento para evitar a avaliação das ações concretas, por parte de órgãos externos (Crubellate et al., 2004). A imposição de claros padrões de desempenho, acoplada à presença de sanções, produz real conformidade, como muitos estudos qualitativos sobre as consequências de sistemas de responsabilidade estatais estão demonstrando (Rowan, 2006, por exemplo).

Oliver (1991) enfatiza que diversos tipos de comportamentos estratégicos podem ser estabelecidos pelas organizações em resposta ao ambiente institucional. Cinco tipos de respostas estratégicas são discutidos pela autora, quais sejam: aquiescência, acordo, evasão, desafio, e manipulação. A Tabela a seguir sintetiza essas respostas estratégicas, as táticas que podem ser utilizadas e exemplifica cada uma delas.

Tabela 1

\section{Respostas Estratégicas aos Processos Institucionais}

\begin{tabular}{lll}
\hline Estratégias & Táticas & Exemplos \\
\hline Aquiescência & Hábito & Seguir normas invisíveis, dadas como certas \\
& Imitar & Imitar modelos institucionais \\
& Aceder & Obedecer às regras e aceitar as normas \\
Compromisso & Equilibrar & Equilibrar as expectativas de públicos múltiplos \\
& Pacificar & Aplacar e acomodar elementos institucionais \\
Barganhar & Negociar com grupos de interesses institucionais \\
Evasão & Ocultar & Disfarçar a não-conformidade \\
& Amortecer & Afrouxar as ligações institucionais \\
& Escapar & Mudar objetivos, atividades ou domínios \\
Desafio & Rejeitar & Desconsiderar normas e valores explícitos \\
& Provocar & Contestar regras e exigências \\
& Atacar & Violar as fontes de pressão institucional \\
Manipulação & Cooptar & Importar pessoas influentes \\
& Influenciar & Moldar valores e critérios \\
& Controlar & Dominar públicos e processos institucionais \\
\hline
\end{tabular}

Nota. Fonte: Oliver, C. (1991). Strategic responses to institutional processes. Academy of Management Review, 16 (1), p. 152.

A aquiescência refere-se ao consentimento das organizações às pressões institucionais; incluem o hábito, a imitação e a conformidade. Nesse caso, pressupõe-se a obediência às normas e regras estabelecidas. O compromisso é representado por uma concordância parcial com os padrões institucionais, desde que os interesses do grupo, ou da organização sejam preservados; é composto pelas táticas de equilibrar, pacificar e barganhar. A evasão é definida como a tentativa organizacional de impossibilitar a conformidade. As organizações conseguem ocultar sua não-conformidade, protegendo-se das pressões institucionais, ou escapando das regras ou das expectativas estabelecidas. 
As táticas da evasão comumente utilizadas são ocultar, amortecer e escapar. O desafio é uma forma mais ativa da resistência aos processos institucionais e utiliza as táticas de rejeição, provocação e ataque. A manipulação é a resposta mais ativa a essas pressões; pode ser conceituada como a tentativa propositada e oportunista de influenciar, ou controlar pressões e avaliações institucionais. Suas táticas mais importantes são a cooptação, influência e controle.

As organizações que utilizam as mesmas estratégias usadas por outras são vistas pelos reguladores e pela sociedade em geral como mais legitimadas do que as organizações que adotam um comportamento fora do que é considerado natural ou habitual (Carstens \& Machado-da-Silva, 2006). A resposta para semelhantes ou diferentes escolhas estratégicas adotadas pelas organizações imersas em rede, pode estar associada com a estrutura da rede social e dinâmica de relacionamento, formada pelas relações sociais entre elas. Dinâmica de relacionamento são as prováveis mudanças ocorridas na estrutura (tamanho, densidade, componentes) de relacionamentos em determinado espaciotemporalidade (Moody, 2004).

A rede social é definida por Wasserman e Faust (1994) como conjunto de atores e as possíveis relações entre eles. As redes sociais, de acordo com Carstens e Machado-da-Silva (2006), são inicialmente estruturadas com a definição de papéis, atribuições e relacionamentos dos atores pertencentes à rede, caracterizando assim o processo de estruturação e isomorfismo, embora as relações de cooperação não eliminem os conflitos e a competição entre os participantes. A concepção estruturalista de capital social enfatiza as vantagens individuais que derivam de características estruturais particulares de suas redes (Rodan \& Galunic, 2004). O sociólogo Burt (1998) refere-se ao capital social como idéias e informações, que surgem e são disseminadas nas relações entre os indivíduos. Este capital é obtido apenas por meio de tais relações, e não como propriedades do indivíduo. O capital social é estruturado por meio das relações estabelecidas entre os atores (Burt, 1998), e não se refere às qualidades do indivíduo, mas às características da rede social na qual este indivíduo está imerso, cujo capital é formado pelas contínuas relações de troca, acumuladas ao longo do tempo (Burt, 1998; Rodan \& Galunic, 2004).

Como entendimentos culturalmente imersos, as instituições especificam e justificam arranjos sociais e comportamentos formal e informal (Garud, Hardy, \& Maguire, 2007). Segundo Hatch (1997) os relacionamentos construídos nas redes por meio das relações de amizade, reputação, ou pelo compartilhamento de ideologias podem mostrar-se mais efetivos pela sua maior capacidade de gerar cooperação e confiança. As relações mútuas em uma rede social também constituem aspecto importante de acesso a novos recursos (Burt, 1992, 1997).

Além disso, as informações são compartilhadas e podem ser disseminadas rapidamente, além de incentivarem novas descobertas. Essas redes também podem ser consideradas alianças estratégicas (Burt, 1992, 1997), que produzem valor estratégico e legitimidade (Dacin, Oliver, \& Roy, 2007).

Esses aspectos devem ser considerados nas relações formadas entre professores vinculados aos programas de pós-graduação (stricto sensu) em administração por meio de co-autorias, porquanto tais relacionamentos são influenciados, direta ou indiretamente, por pressões ambientais. Tais pressões interferem no comportamento dos pesquisadores que fazem parte dos programas, em um nível, assim como nas escolhas estratégicas dos programas, em outro nível, motivadas pelo ambiente no qual estão imersos. Desse modo, consideramos que as respostas estratégicas, oferecidas pelos programas à Capes, podem ser influenciadas pelo ambiente institucional, ainda que tais respostas não envolvam, necessariamente, conscientização ou intencionalidade (Barley \& Tolbert, 1997; Garud et al., 2007; Machado-da-Silva, Fonseca, \& Crubellate, 2005), mas considerando, é claro, que os pesquisadores enquanto agentes de tais programas, tenham suas ações condicionadas pelos seus relacionamentos.

Considerando a abordagem de Burt (1992), na qual a rede parte do indivíduo, salientamos: o que se supõe é que as co-autorias ocorrem por decisão dos próprios professores; mas a rede (composta pelos professores) ocorre como consequência ou em decorrência dos relacionamentos estabelecidos entre eles. Ou seja, o professor opta por ter ou não relação de co-autoria com outros, mas a configuração estrutural da rede é o resultado (não planejado) das relações formadas. 


\section{Procedimentos MetodolóGicos}

O universo da pesquisa foi composto por 32 programas brasileiros de pós-graduação em administração stricto sensu já avaliados pela Capes em 2001 ou em anos anteriores. A presente pesquisa possui perspectiva longitudinal e compreende um período de seis anos, tendo sido analisadas as mudanças incididas ao longo dos triênios de 2001-2003 e 2004-2006.

As etapas que compreenderam a coleta de dados foram as seguintes: (a) inicialmente foram coletados nos sites dos programas de pós-graduação em administração os nomes dos professores que faziam parte de seu quadro docente; (b) em segundo lugar, em meados de 2007, foi realizada uma busca dos currículos disponíveis na plataforma Lattes do CNPq daqueles professores; (c) de posse dos currículos foram identificados os artigos publicados por cada um dos pesquisadores em periódicos, congressos, publicações de livros e capítulos de livros, trabalhos completos publicados em anais de congressos, resumos/resumos expandidos, publicados em anais de congressos. Entre esses artigos, selecionaram-se aqueles com co-autorias, descartando-se aqueles com apenas um autor. Foi considerada toda a produção científica (dentro do critério adotado) do período, o que totalizou 2.062 co-autorias de 2001-2003; e 3.831 co-autorias de 2004-2006 de todos os 703 professores vinculados aos programas pesquisados.

Salientamos, como uma das limitações do estudo, possíveis mudanças ocorridas no corpo docente (entre um triênio e outro), o que não pôde ser considerado aqui, tendo em vista que se optou pela relação de professores de 2007 disponíveis nas páginas dos programas. Entretanto, apesar de este aspecto ser uma das limitações da pesquisa, acreditamos que as mudanças ocorridas não tenham sido tão significativas a ponto de invalidar a pesquisa, porquanto as listas de docentes, indicadas nos sites do programas (do nosso ponto de vista, via de menor impacto), foram cotejadas com a informação prestada no currículo de cada docente, o que nos pareceu e ainda parece mais atualizado do que as informações no site da CAPES.

Com os autores identificados e suas co-autorias foi construída uma matriz de rede 2-mode, que relaciona os autores com os respectivos artigos. Seguindo Rossoni e Hocayen-da-Silva (2008), transformamos a matriz 2-mode em 1-mode, que reflete os relacionamentos, em termos de co-autoria, com cada um dos pesquisadores. Com a matriz de relacionamentos entre pesquisadores disponíveis construímos a matriz de relacionamento entre programas por meio do procedimento Block do UCINET 6 (vide Borgatti, Everett, \& Freeman, 2002; Hanneman \& Riddle, 2005). Basicamente o procedimento consiste em agrupar os relacionamentos em categorias predefinidas que, no nosso caso, eram os programas de pós-graduação.

Após isso, todas as análises dos dados relativos às redes de co-autorias foram realizadas com a utilização dos softwares UCINET 6 (Borgatti et al., 2002) e PAJEK 1.0 (Batagelj \& Mrvar, 2005). Por meio dessa análise, além da verificação da configuração estrutural da rede, também foram calculados graus de intensidade da cooperação (densidade) dos programas, coeficiente de agrupamento, distância média, centralidade de grau, e centralidade de intermediação (Hanneman \& Riddle, 2005), com o intuito de identificar os programas mais relevantes (em termos de co-autoria) na rede. A densidade é a medida de intensidade da interação dos atores da rede com sua mensuração contribui para a formulação de proposições sobre as informações que circulam pela rede, podendo ser desenvolvida tanto para a rede como um todo, quanto para cada um dos programas. Já o coeficiente de agrupamento indica como os contatos de um ator estão recursivamente ligados entre si (Watts \& Strogatz, 1998). Em outras palavras, quanto maior o número de cliques $^{(1)}$ que eles formam, maior o agrupamento da rede. Formalmente, podemos definir o coeficiente de agrupamento CC como 3 x número de cliques/número de trios conectados. Ele pode variar de 0 a 1 , em que as redes totalmente agrupadas apresentam coeficiente 1 , enquanto aquelas totalmente desagrupadas apresentam coeficiente 0 . A distância média indica o número de passos necessários para uma instituição se conectar com qualquer outra na rede. A centralidade de grau (degree centrality) está vinculada ao número de laços que um ator (programa) possui com outros atores dentro de uma rede (Wasserman \& Faust, 1994), embora 
Carpenter e Westphal (2001) lembrem que a quantidade de laços na rede não tem tanta importância quanto o contexto estratégico existente nesses laços. Já a centralidade de intermediação (betweenness centrality) refere-se à intermediação de um ator nas relações com outros atores. Um ator intermediário é aquele que se conecta a outros atores que diretamente não se relacionam entre si (Hanneman \& Riddle, 2005; Wasserman \& Faust, 1994). Não consideramos neste estudo a centralidade de proximidade (closeness centrality) porque, como apontam Rossoni e Guarido Filho (2009), ela apresenta pouco poder explicativo em termos de produção acadêmica.

Adicionalmente, alguns testes estatísticos foram realizados. Como o número de programas avaliados era pequeno e diante da não normalidade dos dados, optamos por utilizar alternativas não paramétricas para comparar as variáveis entre si; neste caso tem-se a correlação de Spearman e, para comparar, os períodos por meio do teste de médias de grupos pareados de Wilcoxon. Ambos os testes foram feitos por meio do pacote estatístico SPSS 15.

Todas as medidas foram calculadas por programa (corpo docente), a partir dos dados individuais. A descrição das etapas da análise dos dados pode ser mais bem visualizada na Tabela 2:

Tabela 2

Etapas da Análise dos Dados

\begin{tabular}{|c|c|c|}
\hline Etapas & Fontes de Dados & Tipo/ Meio de Análise \\
\hline $1^{\text {a }}$ Etapa - Fase I & $\begin{array}{l}\text { Currículos dos professores extraídos } \\
\text { da base Lattes do CNPq. }\end{array}$ & $\begin{array}{l}\text { Análise do número da produção científica e } \\
\text { filiação dos professores vinculados aos } \\
\text { programas pesquisados. }\end{array}$ \\
\hline $1^{\text {a }}$ Etapa - Fase II & $\begin{array}{l}\text { Compilação dos dados extraídos dos } \\
\text { Currículos dos professores da base } \\
\text { Lattes do CNPq. }\end{array}$ & $\begin{array}{l}\text { Estrutura da rede: componentes, densidade, } \\
\text { coeficiente de agrupamento, centralidade de } \\
\text { grau e centralidade de intermediação. } \\
\text { Análise Estatística: Correlação de Spearman } \\
\text { e Teste de Wilcoxon. }\end{array}$ \\
\hline $2^{\mathrm{a}}$ Etapa & $\begin{array}{l}\text { Redes de co-autoria entre professores } \\
\text { dos programas. }\end{array}$ & $\begin{array}{l}\text { Interpretação dos resultados para } \\
\text { formulação de proposições institucionais } \\
\text { concernentes às respostas estratégicas dos } \\
\text { programas à avaliação da Capes. }\end{array}$ \\
\hline
\end{tabular}

Cabe aqui ponderarmos que ações (respostas estratégicas), supostamente adotadas pelos programas por meio das relações entre professores, se justificam pelo fato de que as decisões e ações são originadas dos colegiados de cada programa, que são compostos por professores. A própria natureza estrutural (não burocrática) do programa explica essa escolha (respostas estratégicas dos programas a partir da relação dos professores), tendo em vista que as estratégias não são impostas pelo coordenador, mas partem dos referidos colegiados. Além disso, há que se considerar que a maior parte dos critérios que constam na avaliação da Capes estão diretamente relacionados aos professores, como é caso da avaliação do corpo docente (peso 30\%) e da produção intelectual (peso 35\%), o que nos leva a concluir que $65 \%$ da avaliação de um programa diz respeito diretamente à produção dos professores vinculados a esses programas. Entretanto, lembramos ao leitor que no presente trabalho foi analisada apenas uma parte da produção intelectual dos professores, ou seja, a análise proposta refere-se às relações de co-autorias entre os professores dos programas pesquisados e não a toda a produção acadêmica.

Outra ponderação que fazemos é que as regras utilizadas pelo Sistema de Avaliação da Capes estão disponibilizadas para acesso de coordenadores e do corpo docente dos programas, uma vez que, tanto coordenador quanto professor, são (ou serão) avaliados por tal sistema, como parte do processo avaliativo do programa. Deve-se também levar em consideração que, com a finalidade de atingir o padrão mínimo estabelecido pela Capes, os programas (representados pelo papel do coordenador ou 
pelo colegiado) podem também decidir por criar suas próprias regras (internas ao programa), além daquelas instituídas pelos órgãos externos.

\section{REDE DE CO-AUTORIAS ENTRE OS PROGRAMAS E PROPOSIÇÕES INSTITUCIONAIS}

A elaboração de proposições institucionais foi realizada inicialmente por Crubellate, Rossoni, Mello e Valenzuela (2008), com programas paranaenses de mestrado e doutorado. Apesar de os autores terem considerado o mesmo período de análise, não foi possível verificar as diferenças e/ou mudanças ocorridas nas relações entre os programas de um período para o outro, já que a análise apresentada contemplava o período de 2001-2006, sem considerar as particularidades de cada triênio (2001-2003 e 2004-2006).

Na tabela 3 estão descritos os dados relacionados aos programas (M - mestrado acadêmico; MP mestrado profissional; e D - doutorado) pesquisados no estudo que aqui reportamos.

Tabela 3

Descrição de dados referentes às co-autorias

\begin{tabular}{|c|c|c|c|c|c|}
\hline \multirow[t]{2}{*}{ Instituições/ Programas } & \multirow[t]{2}{*}{$\begin{array}{l}\text { Quant. } \\
\text { docentes }\end{array}$} & \multicolumn{2}{|c|}{ Quant. co-autorias } & \multicolumn{2}{|c|}{$\begin{array}{c}\text { Média de co-autorias por } \\
\text { docente }\end{array}$} \\
\hline & & 2001-2003 & 2004-2006 & 2001-2003 & 2004-2006 \\
\hline $\mathrm{FGV}(\mathrm{RJ})-\mathrm{M} / \mathrm{D}^{* *}$ & 64 & 79 & 134 & 1,234 & 2,094 \\
\hline PUC (RJ) - M/ MP/ D** & 18 & 21 & 39 & 1,167 & 2,167 \\
\hline USP (SP) - M/ D* & 63 & 228 & 429 & 3,619 & 6,81 \\
\hline $\mathrm{FGV}(\mathrm{SP})-\mathrm{M} / \mathrm{MP} / \mathrm{D}$ & 53 & 168 & 250 & 3,17 & 4,717 \\
\hline FJP (MG) - M & 16 & 20 & 15 & 1,25 & 0,938 \\
\hline FPL (MG) - MP & 10 & 32 & 24 & 3,2 & 2,4 \\
\hline FURB (SC) - M & 15 & 80 & 204 & 5,333 & 13,6 \\
\hline PUC (MG) - MP & 19 & 50 & 120 & 2,632 & 6,316 \\
\hline PUC (PR) - M & 18 & 82 & 211 & 4,556 & 11,722 \\
\hline PUC (RS) - M & 14 & 110 & 186 & 7,857 & 13,286 \\
\hline PUC (SP) - M & 15 & 30 & 48 & 2 & 3,2 \\
\hline UEM/ UEL (PR) - M & 16 & 22 & 49 & 1,467 & 3,267 \\
\hline UFBA (BA) - M/ MP/D & 46 & 89 & 119 & 1,935 & 2,587 \\
\hline UFES (ES) - M & 12 & 18 & 35 & 1,5 & 2,917 \\
\hline UFLA (MG) - M/ D & 16 & 52 & 49 & 3,25 & 3,063 \\
\hline UFMG (MG) - M/ D & 22 & 137 & 114 & 6,227 & 5,182 \\
\hline UFPB (PB) - M & 9 & 1 & 0 & 0,111 & 0 \\
\hline UFPE (PE) - M/ D & 22 & 43 & 63 & 1,955 & 2,864 \\
\hline UFPR (PR) - M & 19 & 45 & 101 & 2,368 & 5,316 \\
\hline UFRGS (RS) - M/ D & 43 & 171 & 258 & 3,977 & 6 \\
\hline
\end{tabular}

Continua 
Tabela 3 (continuação)

\begin{tabular}{lccccc}
\hline Instituições/ Programas & $\begin{array}{c}\text { Quant. } \\
\text { docentes }\end{array}$ & \multicolumn{2}{c}{ Quant. co-autorias } & \multicolumn{2}{c}{$\begin{array}{c}\text { Média de co-autorias por } \\
\text { docente }\end{array}$} \\
\hline & & $\mathbf{2 0 0 1 - 2 0 0 3}$ & $\mathbf{2 0 0 4 - 2 0 0 6}$ & $\mathbf{2 0 0 1 - 2 0 0 3}$ & $\mathbf{2 0 0 4 - 2 0 0 6}$ \\
\cline { 2 - 6 } UFRJ (RJ) - M/ D & 28 & 97 & 122 & 3,464 & 4,357 \\
UFRN (RN) - M & 15 & 25 & 75 & 1,667 & 5 \\
UFRRJ (RJ) - MP & 18 & 16 & 45 & 0,889 & 2,5 \\
UFSC (SC) - M & 14 & 26 & 96 & 1,857 & 6,857 \\
UNB (DF) - M & 20 & 39 & 43 & 1,95 & 2,15 \\
UNESA (RJ) - M & 15 & 2 & 69 & 0,133 & 4,6 \\
UNIFACS (BA) - M & 14 & 22 & 30 & 1,571 & 2,143 \\
UNIFOR (CE) - M & 11 & 25 & 30 & 2,273 & 2,727 \\
UNINOVE (SP) - MP & 16 & 68 & 454 & 4,25 & 28,375 \\
UNISANTOS (SP) - M & 7 & 4 & 46 & 0,571 & 6,571 \\
UNISINOS (RS) - M & 15 & 51 & 68 & 3,4 & 4,533 \\
UPM (SP) - M/ D & 20 & 209 & 305 & 10,45 & 15,25 \\
\hline TOTAL & 703 & 2.062 & 3.831 & - & \\
\hline
\end{tabular}

Nota. Fonte: dados da pesquisa

*Campus de São Paulo (SP) ** Mesmo corpo docente

Em relação aos dados da Tabela 3, podemos destacar alguns pontos. Aqueles programas com maior número de docentes, como, por exemplo, FGV-RJ, FGV-SP, UFBA, UFRGS e USP, tendem a apresentar maior número de co-autorias, tanto no primeiro período (Spearman's rho $=0,659$, p. < 0,001 ) quanto no segundo (Spearman's rho $=0,659$, p. $<0,001$ ). No entanto não existe tendência significativa de que quanto maior é o número de docentes no programa, maior e a cooperação (Spearman's rho de 0,283, p. $=0,116$ para o primeiro período e Spearman's rho de 0,060, p. $=0,743$ para o segundo período). Mas, comparando o número de co-autorias com a média, verificamos que eles apresentam correlação forte e significativa nos dois períodos (Spearman's rho de 0,852, p. < 0,001 para o primeiro período e Spearman's rho de 0,768, p. < 0,001 para o segundo período). Esses resultados indicam que, independentemente do número de docentes no programa, há um aumento médio na cooperação entre os programas que, por sua vez, está fortemente e diretamente relacionada ao número de co-autorias de seus pesquisadores. Diante de tal fato, há evidências de que, enquanto estratégia de aumento da qualidade e da produtividade da pesquisa científica, programas e pesquisadores têm papel imbricado no processo.

Além dessas relações, buscamos analisar os dados de forma comparativa entre os triênios, para poder elaborar proposições que contemplem essa possível evolução do campo. A Figura 1, apresentada a seguir, refere-se à rede de relações formada entre programas brasileiros de mestrado e doutorado em administração, por meio de co-autorias nas publicações, no triênio 2001-2003. 


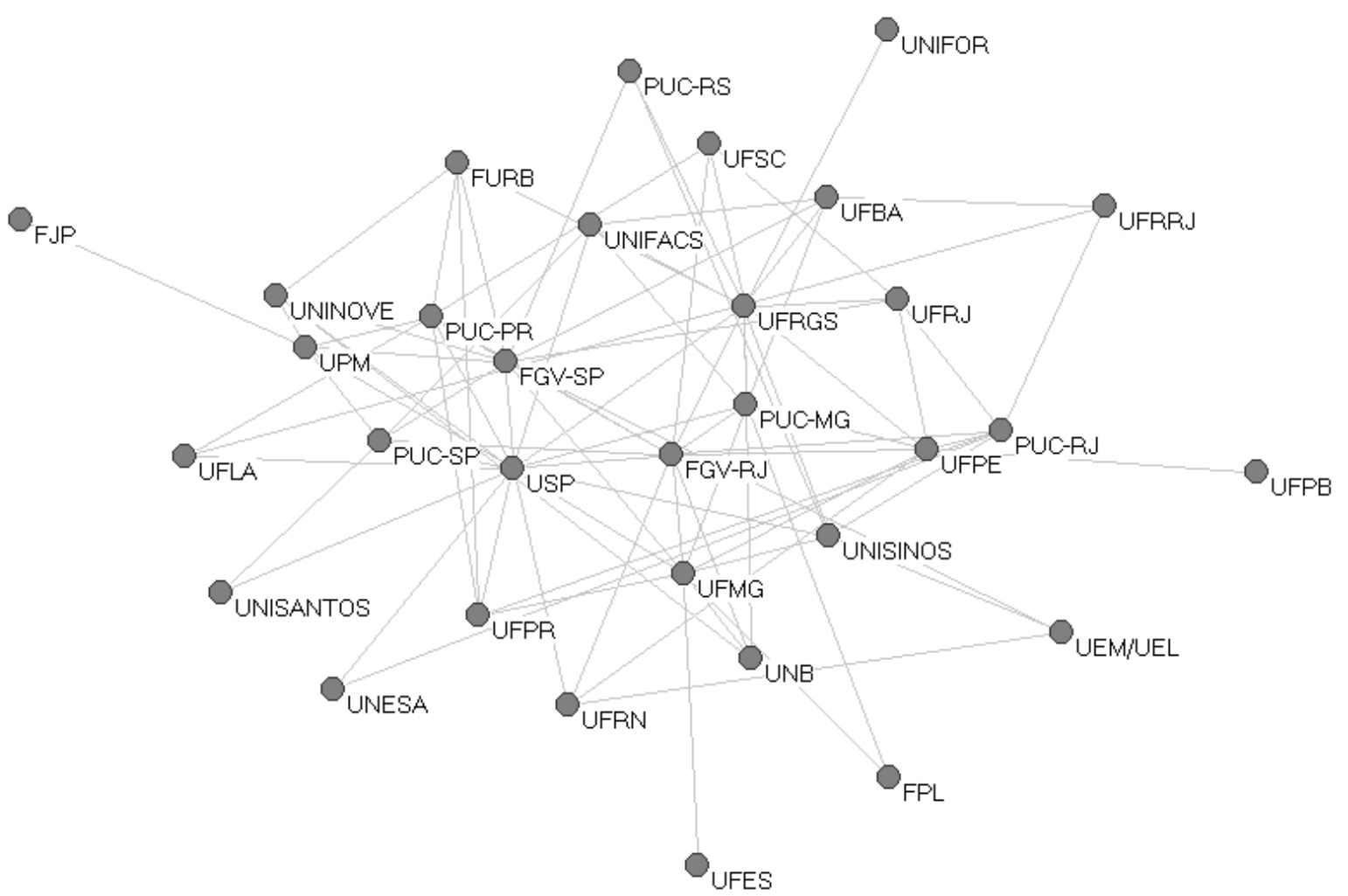

Figura 1. Rede de Relações de Co-autorias entre os Programas no Período de 2001-2003

Pode-se observar que todos os programas estão interligados, formando assim apenas um componente. Os nós estão com o mesmo tamanho porque a intenção é de apenas evidenciar tais relações, desconsiderando o grau de importância dos programas quanto à centralidade. Os programas localizados mais proximamente ao núcleo da rede são considerados centrais e os que se encontram mais afastados do centro são chamados de periféricos. É possível verificar que os programas das instituições FJP, UFES, UFPB e UNIFOR estão conectados à rede apenas por uma linha (co-autoria com apenas uma instituição). Isso significa que sem essa conexão esses programas estariam desconectados da rede e passariam a constituir quatro atores (programas) isolados. Note que tais instituições estão vinculadas a programas com localização mais central na rede e, provavelmente, suas respostas são influenciadas por esses programas.

É importante frisar que nessa análise foram utilizados dados dicotômicos para representar as relações entre os programas e/ou professores, o que significa que foi considerado o número de laços entre eles, porém sem considerar a frequência com que tais laços ocorreram. Isto quer dizer que, mesmo nos casos em que alguns programas e/ou professores aparecem com baixo número de laços, a frequência do número de laços pode ser alta, caracterizando um laço forte, ainda que seja apenas entre dois atores. Por outro lado, existem programas com médio ou grande número de laços que podem, ocasionalmente, apresentar baixa frequência de interações, caracterizando uma situação de laços fracos (Granovetter, 1973).

A Figura 2 mostra a rede de relações dos programas, por meio de co-autorias, no triênio de 20042006. Pode-se observar que a Figura 2 é mais densa e possui maior interligação dos programas. 


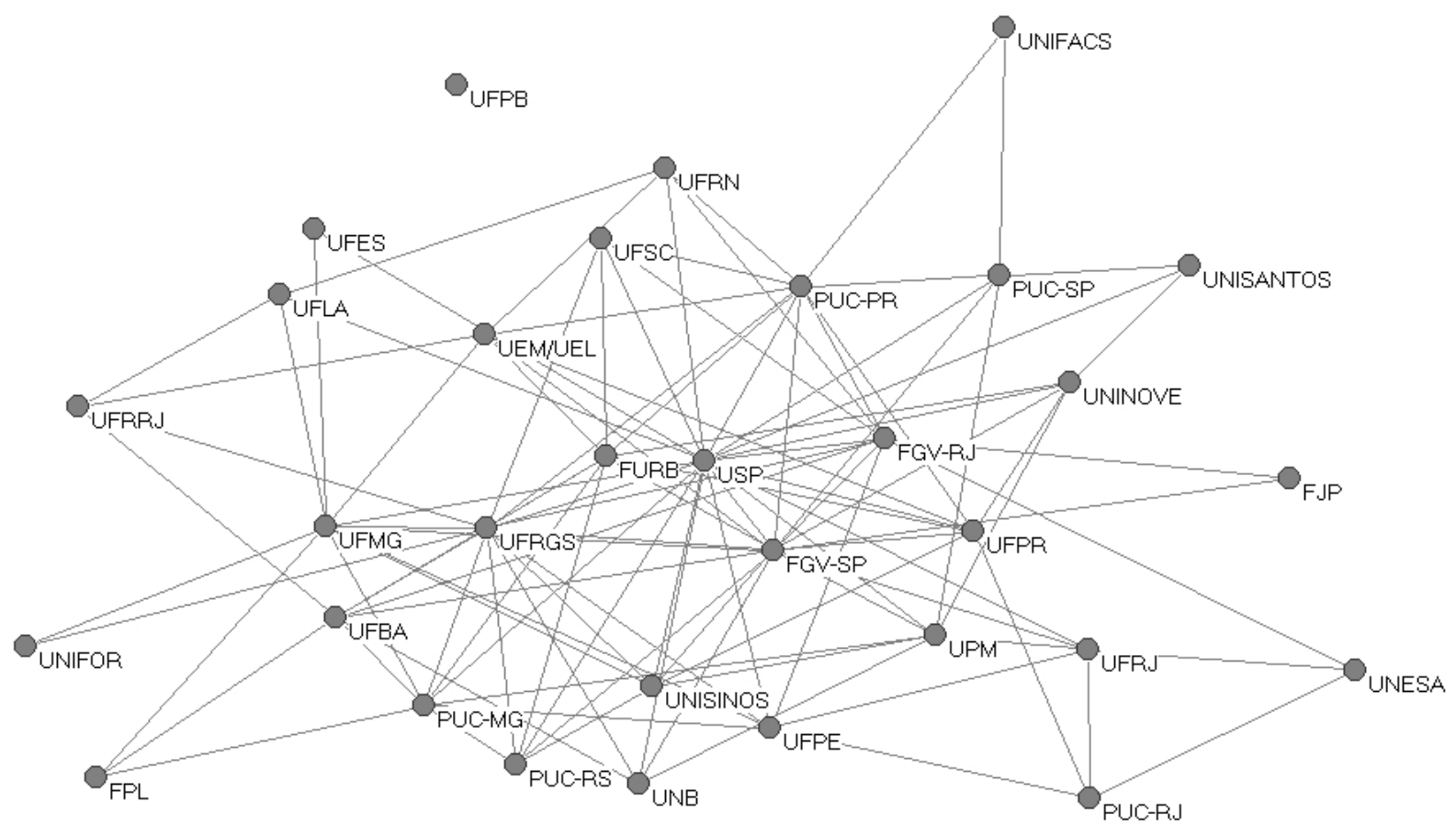

Figura 2. Rede de Relações de Co-autorias entre os Programas no Período de 2004-2006

Nessa rede existe um componente, com 31 programas, e 1 programa isolado apenas. Dos programas que estavam interligados à rede apenas por um vínculo (FJP, UFES, UFPB E UNIFOR), pode-se notar que três deles cooperaram mais no segundo triênio e permaneceram conectados a programas mais centrais e apenas um deles se isolou. O programa da UFPB está isolado por não ter sido realizada nenhuma cooperação nas publicações dos docentes desse programa com docentes de outros programas. Percebe-se ainda que a Figura 2 está mais interconectada que a Figura 1; isso ocorreu porque houve crescimento na colaboração de co-autorias nas publicações científicas entre os programas. A tabela 4 a seguir apresenta os dados relativos às estruturas de relações entre programas nos dois triênios.

Tabela 4

Dados Descritivos das Estruturas de Relações entre Programas

\begin{tabular}{lcc}
\hline & $\begin{array}{c}\text { Triênio } \\
\mathbf{2 0 0 1 - 2 0 0 3}\end{array}$ & $\begin{array}{c}\text { Triênio } \\
\mathbf{2 0 0 4 - 2 0 0 6}\end{array}$ \\
\hline Co-autorias & 2.062 & 3.831 \\
Laços & 860 & 1.450 \\
Média de laços por autor & 5,5 & 6,75 \\
Número de componentes & 1 & 1 \\
Atores isolados & 0 & 1 \\
Tamanho do componente principal & 32 & 31 \\
Distância média & 2,139 & 1,938 \\
Densidade & $17,74 \%$ & $21,77 \%$ \\
Centralização & $36,13 \%$ & $45,59 \%$ \\
Coeficiente de agrupamento & 0,342 & 0,525 \\
\hline
\end{tabular}

Nota. Fonte: dados da pesquisa 
A quantidade de laços refere-se ao número de professores com quem houve a colaboração nas publicações, ou seja, com quem houve relações de co-autorias, sem levar em consideração o número de vezes em que ocorreram tais relações. $\mathrm{O}$ aumento no número de laços revela não só aumento do número de publicações, mas principalmente um crescimento nas colaborações, sob a forma de coautorias entre esses autores.

No segundo período, a intensidade na interação dos programas é mais elevada, como mostra o crescimento no percentual da densidade, o que leva a crer que a comunicação entre eles também foi mais rápida. O aumento da densidade também pode ser observado pela queda na distância média entre os programas, o que indica maior proximidade entre os programas, assim como pelo aumento do coeficiente de agrupamento, que indica que os programas tenderam a se agrupar localmente em mais intensidade no período 2004-2006 do que no período anterior. Outro fato importante é o aumento da centralização das relações, que indica que houve certa hierarquização na cooperação. Isso ocorreu porque aquelas instituições com maior número de laços, que também apresentam maior cooperação com outros programas, têm maior capacidade de receber mais laços que as demais. Esse fenômeno é conhecimento como escolha preferencial (vide Rossoni \& Guarido Filho, 2009), em que instituições mais centrais tendem a ser cada vez mais centrais, ocasionando, na maior parte dos casos, maior hierarquização na rede.

Ainda com relação ao aumento no número de co-autorias de um período para o outro ( $\mathrm{Z}$ de Wilcoxon $=4,432, \mathrm{p}<0,000$ ), é possível supor que o crescimento tenha ocorrido, dentre outros motivos, pelo fato de que a obrigação de padrões de desempenho, juntamente com a existência de sanções, resulta em real conformidade (Rowan, 2006). Ou seja, se os programas não se adequarem aos critérios na avaliação de desempenho da Capes, poderão perder pontuação, o que pode acarretar declínio da nota obtida pelo programa no período anterior. Diante desse argumento, é possível inferir o que segue.

PROPOSIÇÃo 1. No segundo período de avaliação (2004-2006), as respostas dos programas de pós-graduação em Administração no Brasil tenderam a ser mais de aquiescência e compromisso do que no primeiro triênio (2001-2003).

\section{Centralidades de Grau e de Intermediação da Rede de Programas}

A tabela 5 apresenta o índice de centralidade de grau dos programas no período de 2001-2003, onde se relaciona a quantidade de laços de cada programa, bem como o percentual de cada programa em relação aos laços possíveis existentes na rede. Para exemplificar esse ponto, citamos o caso da USP, que possui laços com outros 16 programas, que corresponde a 51,61\% dos laços possíveis (31 laços, excluindo o próprio programa). A centralidade de grau indica o número de laços que um ator possui com outros atores (Hanneman \& Riddle, 2005), quando se identificam os atores sociais (programas) mais relevantes na rede. Nessa mesma tabela também estão relacionados os índices de centralidade de intermediação de cada programa no período que se refere à posição ocupada por um ator em relação a outros pares de atores na rede. Assim, quanto mais pessoas dependem dele para fazer conexões com outras, mais poder o ator (programa) tem. Porém, se dois atores estiverem unidos por mais de um caminho geodésico e tal ator não está em todos eles, perde um pouco de seu poder. Quando possui mais de um canal, o ator torna-se menos dependente e mais poderoso. O poder está além de mera posição ou na identificação de quem possui uma quantidade maior ou menor de poder, mas envolve seu papel estratégico (Hardy \& Clegg, 2001). Através da centralidade de intermediação é possível identificar os atores que detêm um papel estratégico dentro da estrutura da rede. 
Tabela 5

Centralidades de Grau e de Intermediação dos Programas (2001-2003)

\begin{tabular}{|c|c|c|c|c|c|c|c|c|}
\hline \multicolumn{5}{|c|}{ FREEMAN'S DEGREE CENTRALITY MEASURES } & \multicolumn{4}{|c|}{ FREEMAN BETWEENNESS CENTRALITY } \\
\hline & & & & & & \multicolumn{3}{|c|}{ Un-normalized centralization: 3191.562} \\
\hline & & Degree & NrmDegree & Share & & & Betweenness & nBetweenness \\
\hline 32 & USP & 16.000 & 51.613 & 0.091 & 32 & USP & 117.393 & 25.246 \\
\hline 19 & UFRGS & 13.000 & 41.935 & 0.074 & 19 & UFRGS & 74.572 & 16.037 \\
\hline 1 & FGV-RJ & 12.000 & 38.710 & 0.068 & 2 & FGV-SP & 58.189 & 12.514 \\
\hline 2 & FGV-SP & 12.000 & 38.710 & 0.068 & 15 & UFMG & 57.041 & 12.267 \\
\hline 15 & UFMG & 10.000 & 32.258 & 0.057 & 1 & FGV-RJ & 42.510 & 9.142 \\
\hline 6 & PUC-MG & 8.000 & 25.806 & 0.045 & 17 & UFPE & 39.511 & 8.497 \\
\hline 17 & UFPE & 8.000 & 25.806 & 0.045 & 31 & UPM & 30.924 & 6.650 \\
\hline 7 & PUC-PR & 8.000 & 25.806 & 0.045 & 8 & PUC-RJ & 22.131 & 4.759 \\
\hline 8 & PUC-RJ & 7.000 & 22.581 & 0.040 & 6 & PUC-MG & 21.321 & 4.585 \\
\hline 10 & PUC-SP & 6.000 & 19.355 & 0.034 & 7 & PUC-PR & 17.147 & 3.687 \\
\hline 31 & UPM & 6.000 & 19.355 & 0.034 & 30 & UNISINOS & 16.041 & 3.450 \\
\hline 30 & UNISINOS & 6.000 & 19.355 & 0.034 & 12 & UFBA & 11.921 & 2.564 \\
\hline 5 & FURB & 5.000 & 16.129 & 0.028 & 10 & PUC-SP & 7.772 & 1.671 \\
\hline 20 & UFRJ & 5.000 & 16.129 & 0.028 & 18 & UFPR & 6.730 & 1.447 \\
\hline 12 & UFBA & 5.000 & 16.129 & 0.028 & 14 & UFLA & 6.202 & 1.334 \\
\hline 18 & UFPR & 5.000 & 16.129 & 0.028 & 21 & UFRN & 6.127 & 1.318 \\
\hline 28 & UNINOVE & 5.000 & 16.129 & 0.028 & 20 & UFRJ & 5.238 & 1.126 \\
\hline 26 & UNIFACS & 5.000 & 16.129 & 0.028 & 28 & UNINOVE & 5.150 & 1.108 \\
\hline \multicolumn{5}{|c|}{ DESCRIPTIVE STATISTICS } & & \multicolumn{3}{|c|}{ DESCRIPTIVE STATISTICS } \\
\hline & & Degree & NrmDegree & Share & & & Betweenness & nBetweenness \\
\hline 1 & Mean & 5.500 & 17.742 & 0.031 & 1 & Mean & 17.656 & 3.797 \\
\hline 2 & Std Dev & 3.725 & 12.016 & 0.021 & 2 & Std Dev & 26.378 & 5.673 \\
\hline 3 & Sum & 176.000 & 567.742 & 1.000 & 3 & Sum & 565.000 & 121.505 \\
\hline 4 & Variance & 13.875 & 144.381 & 0.000 & 4 & Variance & 695.773 & 32.178 \\
\hline 5 & SSQ & 1412.000 & 14693.028 & 0.046 & 5 & SSQ & 32240.516 & 1491.063 \\
\hline 6 & MCSSQ & 444.000 & 4620.188 & 0.014 & 6 & MCSSQ & 22264.734 & 1029.702 \\
\hline 7 & Euc Norm & 37.577 & 121.215 & 0.214 & 7 & Euc Norm & 179.556 & 38.614 \\
\hline 8 & Minimum & 1.000 & 3.226 & 0.006 & 8 & Minimum & 0.000 & 0.000 \\
\hline 9 & Maximum & 16.000 & 51.613 & 0.091 & 9 & Maximum & 117.393 & 25.246 \\
\hline \multicolumn{5}{|c|}{ Network Centralization = 36.13\% } & \multicolumn{4}{|c|}{ Network Centralization Index = 22.14\% } \\
\hline & Heterog & eneity $=4.5$ & $\%$ Normalizec & $=1.48 \%$ & & & & \\
\hline
\end{tabular}

Note. Fonte: dados da pesquisa. 
Se um ator (programa) recebe muitos laços, pode-se pressupor que ele seja mais proeminente ou que possua elevado prestígio (Hanneman \& Riddle, 2005; Moody, 2004), o que pode indicar a sua importância e influência em relação aos outros (Hanneman \& Riddle, 2005). Dessa forma, parece plausível supor o que segue.

PROPOSIÇÃO 2. No primeiro triênio, programas que cooperaram diretamente com os que possuíam maior centralidade (USP, FGV-SP, FGV-RJ, UFRGS) possivelmente ofereceram respostas à avaliação da Capes semelhantes a tais programas com os quais se relacionaram.

Os atores que têm mais laços em relação aos outros tendem a ocupar posições mais vantajosas, apresentam modos alternativos de satisfazer necessidades e são menos dependentes de outros atores. Mais conexões significa, muitas vezes, que os indivíduos estão expostos a uma maior quantidade e diversidade de informações. Os indivíduos mais conectados tanto podem influenciar como serem influenciados por outros. $\mathrm{O}$ fato de ter maior quantidade de laços pode significar maior facilidade em atrair e ter acesso a mais recursos. As populações mais conectadas também podem ser mais capazes de mobilizar seus recursos e ser mais capacitadas a apresentar múltiplas e diversas perspectivas para resolver problemas (Hanneman \& Riddle, 2005). Quanto mais elevado o coeficiente de variação, mais heterogênea a população quanto à influência e proeminência, no que se refere à quantidade de laços que um ator possui com outro.

PROPOSIÇÃO 3. Os programas que apresentaram maior número de laços, no primeiro triênio, possivelmente também exerceram maior grau de influência nas respostas desenvolvidas ao modelo de avaliação estabelecido pela Capes, naquele período.

Programas centrais estão mais propensos a serem mimetizados, pois as organizações tendem a imitar aquelas que lhes parecem mais bem-sucedidas ou que apresentam maior legitimidade (DiMaggio \& Powell, 1991). Esse comportamento também pode ser associado ao pilar cultural-cognitivo de Scott (2001), cuja legitimidade proveniente está baseada na adoção de ações percebidas como certas (taken for granted) e significados aceitos pelo ambiente, como condição necessária para a sobrevivência das organizações. Então, parece cabível supor o seguinte.

PROPOSIÇÃO 4. Os programas que apresentam maior centralidade na rede (USP, UFRGS, FGVRJ, FGV-SP, UFMG, PUC-MG, UFPE, PUC-PR, PUC-RJ, PUC-SP, UPM, UNISINOS, FURB, UFRJ, UFBA, UFPR, UNINOVE, UNIFACS), provavelmente, foram mais mimetizados do que aqueles com menor centralidade, no primeiro triênio, pelo fato de serem os mais centrais na rede.

Conforme menciona Moody (2004), a centralidade de grau pode explicar as razões pelas quais alguns pesquisadores conseguem disseminar de modo mais rápido suas ideias no ambiente acadêmico. Autores que possuem muitos cooperadores são também considerados os mais influentes (Burt, 1992; Moody, 2004). Dessa forma, pressupõe-se o seguinte.

PROPOSIÇÃO 5. No primeiro triênio, os programas com maior número de laços, (USP; UFRGS; FGV-RJ; FGV-SP; UFMG; PUC-MG; UFPE; PUC-PR; PUC-RJ; PUC-SP; UPM e UNISINOS) provavelmente foram também os mais influentes nas respostas à avaliação da Capes naquele período.

A tabela a seguir refere-se à centralidade de grau e à centralidade de intermediação dos programas pesquisados em relação ao segundo triênio. A tabela apresenta o índice de centralidade de grau dos programas no período de 2004-2006, em que se relaciona a quantidade de laços de cada programa e o percentual de cada programa em relação aos laços possíveis existentes na rede. Também estão relacionados nesta tabela os índices de centralidade de intermediação de cada programa no período supramencionado, que se refere à posição ocupada por um ator em relação a outros pares de atores na rede, conforme explicação anterior na descrição da tabela 5. 
Tabela 6

Centralidades de Grau e de Intermediação dos Programas (2004-2006)

\begin{tabular}{|c|c|c|c|c|c|c|c|c|}
\hline \multicolumn{5}{|c|}{ FREEMAN'S DEGREE CENTRALITY MEASURES } & \multicolumn{4}{|c|}{ FREEMAN BETWEENNESS CENTRALITY } \\
\hline & & & & & & \multicolumn{3}{|c|}{ Un-normalized centralization: 2941.578} \\
\hline & & Degree & NrmDegree & Share & & & Betweenness & nBetweenness \\
\hline 32 & USP & 20.000 & 64.516 & 0.093 & 32 & USP & 105.549 & 22.699 \\
\hline 2 & FGV-SP & 17.000 & 54.839 & 0.079 & 2 & FGV-SP & 59.808 & 12.862 \\
\hline 19 & UFRGS & 15.000 & 48.387 & 0.069 & 19 & UFRGS & 46.658 & 10.034 \\
\hline 7 & PUC-PR & 11.000 & 35.484 & 0.051 & 15 & UFMG & 33.555 & 7.216 \\
\hline 15 & UFMG & 11.000 & 35.484 & 0.051 & 1 & FGV-RJ & 32.847 & 7.064 \\
\hline 1 & FGV-RJ & 10.000 & 32.258 & 0.046 & 7 & PUC-PR & 29.435 & 6.330 \\
\hline 5 & FURB & 10.000 & 32.258 & 0.046 & 18 & UFPR & 14.197 & 3.053 \\
\hline 6 & PUC-MG & 9.000 & 29.032 & 0.042 & 12 & UFBA & 14.106 & 3.033 \\
\hline 12 & UFBA & 8.000 & 25.806 & 0.037 & 17 & UFPE & 13.061 & 2.809 \\
\hline 18 & UFPR & 8.000 & 25.806 & 0.037 & 6 & PUC-MG & 12.950 & 2.785 \\
\hline 31 & UPM & 8.000 & 25.806 & 0.037 & 5 & FURB & 11.950 & 2.570 \\
\hline 30 & UNISINOS & 7.000 & 22.581 & 0.032 & 20 & UFRJ & 11.873 & 2.553 \\
\hline 17 & UFPE & 7.000 & 22.581 & 0.032 & 10 & PUC-SP & 10.099 & 2.172 \\
\hline 11 & UEM/UEL & 7.000 & 22.581 & 0.032 & 11 & UEM/UEL & 8.778 & 1.888 \\
\hline 20 & UFRJ & 6.000 & 19.355 & 0.028 & 31 & UPM & 7.346 & 1.580 \\
\hline 28 & UNINOVE & 6.000 & 19.355 & 0.028 & 28 & UNINOVE & 4.067 & 0.875 \\
\hline 9 & PUC-RS & 6.000 & 19.355 & 0.028 & 14 & UFLA & 3.454 & 0.743 \\
\hline 10 & PUC-SP & 6.000 & 19.355 & 0.028 & 21 & UFRN & 3.201 & 0.688 \\
\hline \multicolumn{5}{|c|}{ DESCRIPTIVE STATISTICS } & & \multicolumn{3}{|c|}{ DESCRIPTIVE STATISTICS } \\
\hline & & Degree & NrmDegree & Share & & & Betweenness & nBetweenness \\
\hline 1 & Mean & 6.750 & 21.774 & 0.031 & 1 & Mean & 13.625 & 2.930 \\
\hline 2 & Std Dev & 4.430 & 14.290 & 0.021 & 2 & Std Dev & 21.900 & 4.710 \\
\hline 3 & Sum & 216.000 & 696.774 & 1.000 & 3 & Sum & 436.000 & 93.763 \\
\hline 4 & Variance & 19.625 & 204.214 & 0.000 & 4 & Variance & 479.593 & 22.180 \\
\hline 5 & SSQ & 2086.000 & 21706.557 & 0.045 & 5 & SSQ & 21287.463 & 984.505 \\
\hline 6 & MCSSQ & 628.000 & 6534.859 & 0.013 & 6 & MCSSQ & 15346.963 & 709.768 \\
\hline 7 & Euc Norm & 45.673 & 147.331 & 0.211 & 7 & Euc Norm & 145.902 & 31.377 \\
\hline 8 & Minimum & 0.000 & 0.000 & 0.000 & 8 & Minimum & 0.000 & 0.000 \\
\hline 9 & Maximum & 20.000 & 64.516 & 0.093 & 9 & Maximum & 105.549 & 22.699 \\
\hline \multicolumn{5}{|c|}{ Network Centralization $=45.59 \%$} & \multicolumn{4}{|c|}{ Network Centralization Index $=20.41 \%$} \\
\hline
\end{tabular}

Nota. Fonte: dados da pesquisa 
Os programas que apresentaram maior índice de centralidade (da primeira à quarta posição) foram os programas da USP; FGV-SP; UFRGS e PUC-PR, seguidos de outros programas com índices também significativos. Na discussão das relações formadas por meio das redes, admite-se que os atores considerados mais centrais também sejam os mais influentes, conforme já foi dito anteriormente. Sendo assim, infere-se o seguinte.

PROPOSIÇÃO 6. Provavelmente, no segundo triênio, os programas (USP, FGV-SP, UFRGS, PUC-PR, UFMG, FGV-RJ, FURB, PUC-MG) exerceram maior influência sobre os programas com os quais se relacionaram, e responderam de modo semelhante, independentemente do tipo de resposta: se é aquiescência, acordo, evasão, desafio, ou manipulação.

Os programas que não estão descritos na tabela 6 e que apresentam cinco laços são: UFRN, UNB e UFSC; com quatro laços: UFRRJ, PUC-RJ e UFLA; com três laços: UNISANTOS, UNESA e FPL, e com dois laços: FJP, UFES, UNIFACS e UNIFOR. Programas com baixo número de conexões tendem a responder mais lentamente, independentemente do tipo de resposta. Já os programas com maior quantidade de conexões e maior densidade tendem a formar redes mais robustas com maior capacidade de responder rapidamente e efetivamente.

PROPOSIÇÃO 7. No triênio 2004-2006, possivelmente os programas da UFRN, UNB, UFSC, UFRRJ, PUC-RJ, UFLA, UNISANTOS, UNESA, FPL, FJP, UFES, UNIFACS e UNIFOR responderam mais lentamente às exigências da Capes do que os programas da USP, FGV-SP, UFRGS, PUC-PR, UFMG, FGV-RJ, FURB, PUC-MG UFBA, UFPR, UPM, UNISINOS, UFPE, UEM/UEL, UFRJ, UNINOVE, PUC-RS, PUC-SP

As ligações mais curtas (com distância geodésica menor) entre os atores significam que os atores são mais influentes ou mais centrais. Desse modo, conhecer o número de laços e a distância entre eles em uma rede é muito importante à compreensão das restrições e oportunidades do indivíduo e contribui para entender o comportamento da rede como um todo. Levando em consideração que maior quantidade de ligações significa também maior influência, propõe-se o que segue:

PROPOSIÇÃO 8: Os programas da USP, FGV-SP, UFRGS, PUC-PR, UFMG, FGV-RJ, FURB, PUC-MG UFBA, UFPR, UPM, UNISINOS, UFPE, UEM/UEL, UFRJ, UNINOVE, PUC-RS, PUCSP, possivelmente foram mais influentes nas respostas do que os programas da UFRN, UNB, UFSC, UFRRJ, PUC-RJ, UFLA, UNISANTOS, UNESA, FPL, FJP, UFES, UNIFACS e UNIFOR no segundo triênio.

Respostas do tipo desafio e manipulação têm ocorrência mais provável, quando o grau de interconexão organizacional no ambiente institucional é baixo (Oliver, 1991): programas que apresentaram menor índice de conexão estão mais propensos a oferecer as respostas acima mencionadas. Os programas que apresentaram baixa conexão foram os da PUC-RS, UEM/UEL, UFRRJ, UFLA (2001-2003), UNIFACS (2004-2006), UNISANTOS, UNESA, FPL, FJP, UFES, UNIFOR e UFPB (nos dois triênios). Então, pressupõe-se o seguinte:

PROPOSIÇÃO 9. Os programas vinculados à UNISANTOS, UNESA, FPL, FJP, UFES, UNIFOR e UFPB (em maior grau), UEM/UEL, UFRRJ, UFLA, UNIFACS (em menor grau), possivelmente, apresentaram, no segundo triênio, respostas estratégicas do tipo desafio e manipulação.

Ressaltamos que não se pode afirmar que todos os programas vinculados por meio das co-autorias aos de baixa conexão apresentaram esse mesmo tipo de respostas (desafio e manipulação), tendo em vista que existem programas com alto grau de centralidade ligados a esses, e com maior tendência a oferecer respostas de aquiescência e de conformidade.

A Figura 3 refere-se aos índices de densidade e coeficiente de agrupamento das redes de cooperação dos programas. A densidade é definida como força média de todos os laços possíveis (Acedo, Barroso, Casanueva, Galán, 2006; Hanneman \& Riddle, 2005; Nooy, Mrvar, \& Batagelj, 2005). A medida da densidade contribui para a formulação de proposições sobre as informações que circulam pela rede. Já 
o coeficiente de agrupamento é a medida da densidade local. $\mathrm{O}$ índice varia de 0 a 1 ; quanto mais próximo de 1, maior agrupamento local. Essas medidas provêm insights e contribuem para a elaboração de novas proposições.

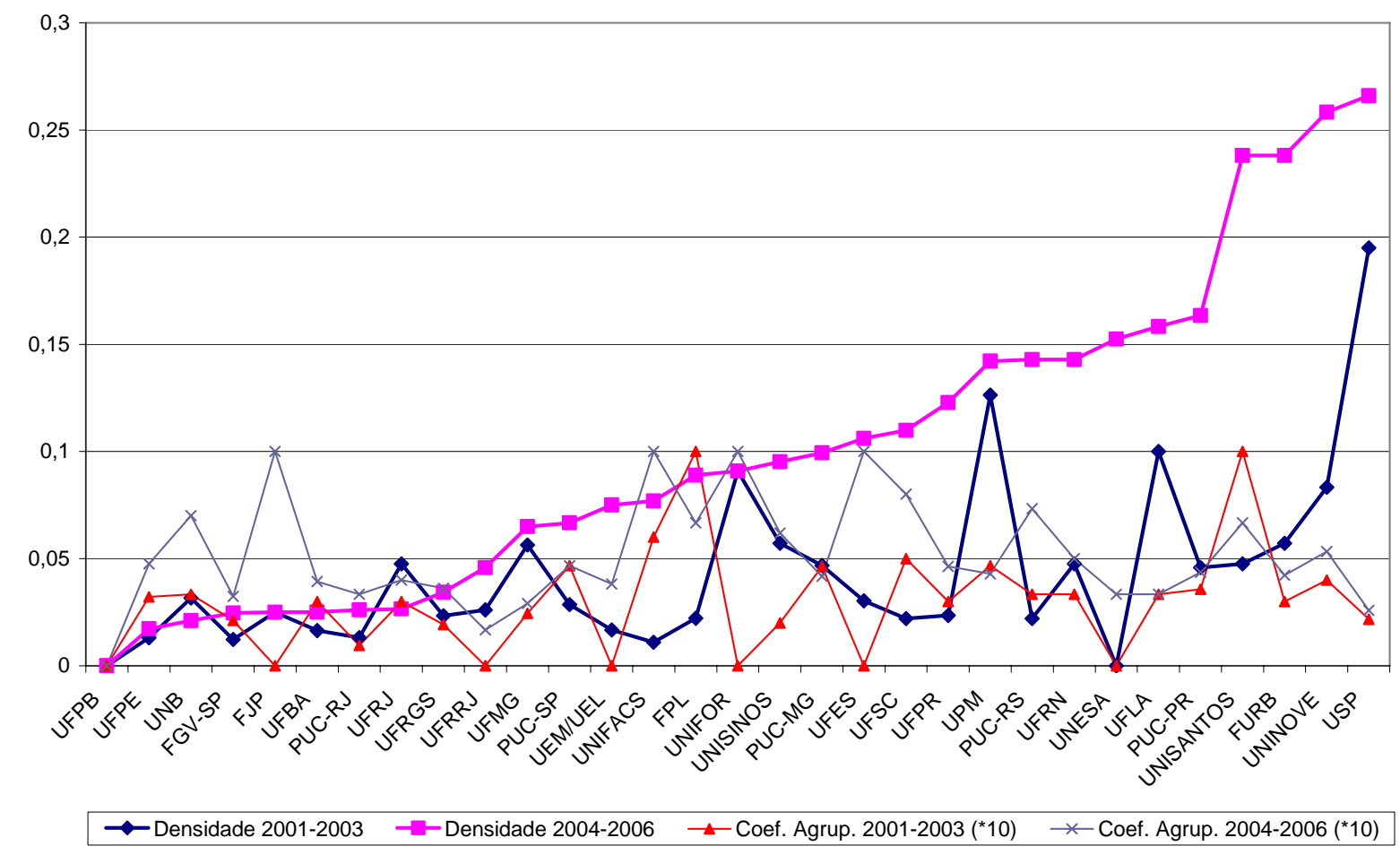

Figura 3. Densidade e Coeficiente de Agrupamento dos Programas

Em relação ao coeficiente de agrupamento, é importante frisar: aqueles programas que estão isolados ou que não fazem parte de nenhum clique apresentam coeficiente de agrupamento 0. Clique é um aglomerado de nós conectados entre si, relacionado com a mutualidade dos laços relacionais: medir até que ponto as escolhas de indivíduos, imersas em subgrupo, são mútuas.

Redes densas possuem distâncias geodésicas menores, o que indica que as informações tendem a fluir mais rapidamente. No caso das redes difusas, as distâncias são maiores e as informações nessas redes fluem mais lentamente. As populações com alta densidade respondem diferentemente aos desafios do ambiente do que aquelas que apresentam baixa densidade.

Maior densidade denota maiores alternativas de ação como também suas maiores limitações. O programa da USP é o único que no primeiro período obteve maior densidade que a densidade da rede. Já no segundo triênio foram quatro os programas que apresentaram densidade maior que a densidade da rede, USP, UNINOVE, UNISANTOS e FURB. Isso significa o seguinte.

PROPOSIÇÃo 10. Programas com densidade interna mais alta, como os da USP, UPM, UFLA, UNIFOR, UNINOVE, UNISINOS, FURB, UFMG, UNISANTOS, UFRN, UFRJ, PUC-MG e PUCPR, provavelmente responderam com maior velocidade aos critérios de avaliação da Capes que os demais programas, no primeiro triênio. No segundo triênio, provavelmente os programas da USP, UNINOVE, UNISANTOS, FURB, PUC-PR, UFLA, UNESA, UFRN, PUC-RS, UPM, UFPR, UFSC, UFES, PUC-MG, UNISINOS, UNIFOR, FPL, UNIFACS, UEM/UEL, PUC-SP e UFMG responderam mais rapidamente às pressões advindas da avaliação da Capes.

É importante salientar que onde o grau de densidade é menor haverá sempre respostas não coesas, independentemente das respostas. Consideramos respostas dos programas não coesas entre si, e também não coesas às pressões e orientações provenientes da CAPES. Assim: 
PROPOSIÇÃo 11. No primeiro triênio, os programas da UNB, UFES, PUC-SP, UFRRJ, FJP, UFPR, UFRGS, FPL, UFSC, PUC-RS, UEM/UEL, UFBA, PUC-RJ, UFPE, FGV-SP, UNIFACS, FGV-RJ, UNESA e UFPB, por possuírem níveis mais baixos de densidade, provavelmente ofereceram respostas não coesas ou respostas não coerentes entre si. Já no segundo triênio, aqueles que provavelmente ofereceram respostas não coesas foram os programas da UFRRJ, UFRGS, UFRJ, PUCRJ, UFBA, FJP, FGV-SP, UNB, UFPE, FGV-RJ e UFPB.

Os atores centrais de uma rede densa tenderão a ser muito influentes naquela rede. No caso dos programas, se esses atores são vinculados à Capes como membros do comitê avaliador, então é de se esperar que os programas nesta rede aquiesçam mais em relação aos critérios estabelecidos pela Capes. A comissão de avaliação da Capes de 2004 (que avaliou os programas no triênio 2001-2003) foi composta por professores vinculados às seguintes instituições de ensino superior: INC (2 docentes); FGV/SP (2 docentes); FUCAPE (1 docente); PUC/SP (2 docentes); UFPR (2 docentes); UNB (1 docente); e UPM (2 docentes). O comitê avaliador de 2007 (que avaliou o triênio 2004-2006) foi formado por professores pertencentes a: FGV/RJ (1 docente); FGV/SP (2 docentes); FURB (1 docente); PUC/MG (1 docente); PUC/PR (1 docente); PUC/RS (1 docente); UFBA (1 docente); UFLA (1 docente); UFMG (1 docente); UFPE (2 docentes); UFPR (1 docente); UFRGS (1 docente); UFRJ (1 docente); UFRN (1 docente); UFSC (1 docente); UNB (3 docentes); UNICENP (1 docente); UNISINOS (1 docente); UPM (1 docente); USP (3 docentes). A relação com os nomes dos docentes pertencentes ao comitê de avaliação da Capes de 2004 e 2007 está contida nos formulários (ficha de avaliação) dos programas avaliados.

Dentre os programas que apresentaram maior densidade e que apresentam, em seu quadro de professores, representantes no comitê avaliador da Capes, estão os programas da UPM com dois docentes, referente ao primeiro triênio; da USP com três docentes, e os programas da FURB, PUC-PR, UFLA, UFRN, PUC-RS, UPM, UFPR, UFSC, PUC-MG, UNISINOS, e UFMG com um docente membro do comitê avaliador em cada programa referente ao segundo triênio. Desse modo, é admissível supor o seguinte.

PROPOSIÇÃO 12. Os programas da UPM (no primeiro triênio), e da USP, FURB, PUC-PR, UFLA, UFRN, PUC-RS, UPM, UFPR, UFSC, PUC-MG, UNISINOS, UFMG (no segundo triênio) provavelmente aceitaram, em maior grau, as exigências provenientes da Capes, oferecendo respostas de aquiescência e compromisso.

Apesar da baixa conexão da PUC-RS com outros programas, estamos supondo resposta de aquiescência e compromisso, porque há, vinculado a esse programa, um professor membro do comitê avaliador. O desvio padrão é também uma fonte de informação sobre o modo de pensar de cada ator. Os atores com poucos ou muitos laços externos têm menor variabilidade de respostas do que aqueles com níveis médios de laços. Isto significa que tais atores são mais previsíveis no seu comportamento do que aqueles com números intermediários de laços. De certo modo, os atores com muitos laços (no centro de uma rede) e atores na periferia de uma rede (poucos laços) têm modelos de comportamento mais limitados (restritos) e previsíveis. Organizações que usam estratégias semelhantes àquelas adotadas por outras são vistas tanto pelos reguladores como pela sociedade como sendo mais legitimadas do que aquelas que utilizam um comportamento diferente do padrão (Carstens \& Machado-da-Silva, 2006). Os atores com poucos laços podem variar mais no seu comportamento; na dependência de estarem conectados com estas ou aquelas entidades, terão maior tendência a responder diferentemente do padrão predominante nos programas centrais da rede. Sendo assim, é provável o que segue.

PROPOSIÇÃO 13. Os programas considerados periféricos (com menor número de laços e mais afastados do centro da rede) têm menor probabilidade de serem mimetizados, porquanto as organizações estão mais propensas a imitar aquelas que lhes parecem ter maior legitimidade (DiMaggio \& Powell, 1991).

PROPOSIÇÃo 14. Possivelmente aqueles que apresentaram poucos laços no primeiro período, como os programas da PUC-RS, UEM/UEL, UFRRJ, UFLA, UNISANTOS, UNESA, FPL, FJP, 
UFES, UNIFOR, UFPB e os programas da UNISANTOS, UNESA, FPL, FJP, UFES, UNIFACS, UNIFOR e UFPB, no segundo triênio, ofereceram respostas diferentes (respostas do tipo evasão, desafio ou manipulação) do padrão predominante (respostas de aquiescência e compromisso) nos programas centrais.

\section{CONCLUSÕES}

De uma perspectiva longitudinal, propôs-se nesse estudo, a partir da análise da rede de co-autorias formada por professores dos programas de pós-graduação em administração descrever e analisar as mudanças ocorridas na configuração estrutural dessas redes e elaborar proposições institucionais das prováveis respostas estratégicas, fundamentadas, especialmente na tipologia de Oliver (1991) e nas especificidades da análise de redes oferecidas à avaliação da Capes pelos programas considerados.

A configuração relacional e estrutural da rede foi obtida a partir da análise de redes, com a utilização dos softwares UCINET 6.0 (Borgatti et al., 2002) e PAJEK 1.10 (Batagelj \& Mrvar, 2005). A metodologia utilizada constitui uma das diversas possibilidades existentes para análise. Faz-se necessário verificar também outros fatores que exercem influência nas relações sociais entre os programas que influenciam também e podem justificar a escolha das respostas estratégicas.

Na concepção de Scott (2001) os atores (no caso os programas brasileiros de pós-graduação stricto sensu em administração), pertencentes ao mesmo campo, tendem a aceitar as mesmas crenças e aderir a elas, o que condiciona suas ações. Desse modo, é plausível inferir que programas que interagem entre si por meio de co-autorias com seus docentes e pesquisadores tendem a desenvolver padrões cognitivos e interpretativos semelhantes e, consequentemente, a responder também de modo semelhante.

Programas com maior índice de centralidade de grau estão mais propensos a oferecer respostas de aquiescência aos critérios da Capes e, provavelmente, a influenciar a resposta daqueles programas que mantêm relações diretas com eles. Programas que possuem muitos cooperadores são considerados os mais influentes na capacidade de disseminar ideias e informações. A pesquisa constatou queda no índice da centralidade de intermediação de um triênio para o outro, em relação a alguns programas, o que provavelmente indica perda de poder de controle sobre as relações entre os atores (programas). Esse fato pode ter ocorrido por causa de alguns fatores, tais como: a criação de novos relacionamentos de co-autoria com professores pertencentes a programas não pesquisados, entrada e credenciamento de novos programas de pós-graduação na área e, consequentemente, o estabelecimento de novas relações com esses programas.

O acompanhamento da Capes, além de avaliar os programas e de indicar suas potencialidades e pontos fracos, funciona também como balizador para distribuição de recursos financeiros aos alunos de mestrado e doutorado (Machado-da-Silva, 2003). Um dos critérios mais importantes para a avaliação do Programa é a produção acadêmica, cujas relações de co-autorias podem ser utilizadas como indicador de produção, o que, por sua vez, constitui fator relevante para acesso direto ou indireto aos recursos. Da perspectiva da dependência de recursos, uma organização será conduzida também por seus próprios interesses, a fim de reduzir a incerteza, conflito e instabilidade (Oliver, 1991). Nessa perspectiva, as organizações manipulam o ambiente em benefício próprio, exercendo papel ativo em face das forças ambientais (Rossetto \& Rossetto, 2005).

As interações podem ainda rejeitar ou reforçar pressões institucionais advindas da Capes por meio da avaliação trienal desses programas. Assim, os resultados apresentados fornecem subsídios necessários para concluir que existem diferentes respostas oferecidas pelos programas, na sua maioria representadas por ações de aquiescência e compromisso. Por outro lado, é necessário chamar a atenção para o fato de que a menção a possíveis respostas estratégicas de rejeição, em algum grau, dos padrões e orientações avaliativas da CAPES não pode e não deve ser interpretada como negativa, em termos 
absolutos. Se tais respostas de fato se efetivaram naqueles triênios analisados, elas certamente não ultrapassaram o limite do que o Estado e o campo definem como legalmente legítimo ou nem sequer foram intensas, a ponto de arriscar a existência daqueles programas. Não se pode desconsiderar o fato, aceito no âmbito da própria teoria institucional e de outras teorias organizacionais, de que criatividade e geração de ações e soluções alternativas estão relacionadas a respostas de rejeição, em algum grau, das estruturas institucionais existentes. Essa tensão entre manutenção e mudança é, mesmo do ponto de vista institucional, comum à maioria dos campos sociais e dá origem à dinâmica entre forças pró e contra mudanças, além de definir os graus e os ritmos de mudança.

Como direção para pesquisas futuras, faz-se necessário, conforme sugerem Selltiz, Jahoda, Deutsch e Cook (1975), verificar se as proposições elaboradas a partir da investigação exploratória têm aplicabilidade geral. A provável aceitação dos padrões de desempenho exigidos poderá ser confirmada por meio de investigações específicas, tanto quantitativa como qualitativamente. Outros estudos poderiam ser realizados, visando, além de descrever, também interpretar as respostas estratégicas efetivamente adotadas pelos programas, a partir das suposições aqui levantadas. As relações, aqui estabelecidas, entre cooperação e co-autoria devem ser testadas por outros estudos, visando a investigar os processos de mútua influência e transferência de informações, básicos para entendimento da elaboração de respostas estratégicas. O esforço inicial desta pesquisa foi no sentido de analisar a importância das redes estabelecidas entre os pesquisadores da Administração, no período aqui investigado, e não reproduzir as características relacionais de redes da mesma natureza em outros contextos acadêmico-científicos, em outras áreas científicas do país e de outros países. Espera-se que os pressupostos aqui estabelecidos possam constituir a base inicial para novas pesquisas empíricas que possibilitem melhor compreensão do processo da recursividade entre o ambiente institucional e as ações organizacionais.

\section{NOTA}

${ }^{1}$ Clique é uma sub-rede ou subgrafo completo de três ou mais nós, em que todos os pontos estão diretamente conectados (Nooy et al., 2005; Wasserman \& Faust, 1994).

\section{REFERÊNCIAS}

Acedo, F., Barroso, C., Casanueva, C., \& Galán, J. (2006). Co-authorship in management and organizational studies: an empirical and network analysis. Journal of Management Studies, 43(5), 957-983.

Alperstedt, G. D., Martignago, G., \& Fiates, G. G. S. (2006). O processo de adaptação estratégica de uma instituição de ensino superior sob a ótica da teoria institucional. Revista de Ciências da Administração, 8(15), 1-24.

Barley, S., \& Tolbert, P. (1997). Institutionalization and structuration: studying the links between action and institution. Organization Studies, 18(1), 93-117.

Batagelj, V., \& Mrvar, A. (2005). PAJEK - Program for analysis and visualization of large networks. Ljubljana, Slovenia: University of Ljubljana.

Bidwell, C. (2006). Varieties of institutional theory: traditions and prospects for educational research. In H. Meyer \& B. Rowan (Eds.), The new institutionalism in education (pp. 33-50). Albany: State University of New York Press. 
Blau, P. M. (1970). A formal theory of differentiation in organizations. American Sociological Review, 35(2), 201-218.

Borgatti, S. P., Everett, M. G., \& Freeman, L. C. (2002). Ucinet for windows: software for social network analysis. Boston: Harvard Analytic Technologies.

Burt, R. (1992). Structural holes: the social structure of competition. Cambridge, MA and London: Havard University Press.

Burt, R. (1997). The contingent value of social capital. Administrative Science Quarterly, 42(2), 339365.

Burt, R. (1998). The gender of social capital. Rationality and Society, 10(1), 5-46.

Carpenter, M. A., \& Westphal J. D. (2001). The strategic context of external network ties: examining the impact of director appointments on board involvement in strategic decision making. Academy of Management Journal, 44(4), 639-660.

Carstens, D. D. S., \& Machado-da-Silva, C. L. (2006, setembro). Estratégia e estrutura de relacionamentos na rede de Empresas Alpha. Anais do Encontro Nacional da Associação Nacional de Pós-Graduação e Pesquisa em Administração, Salvador, BA, Brasil, 30.

Cochia, C. B. R., \& Machado-da-Silva, C. L. (2004). Ambiente, interpretação e estratégia em organizações paranaenses dos setores de vestuário e de alimentos. Revista de Administração Contemporânea, 8(Edição Especial), 11-35.

Conselho Nacional de Desenvolvimento Científico e Tecnológico. (2009). CNPq - Número de bolsasano no país e no exterior - 1951-2009. Recuperado em 28 abril, 2010, de http://www.cnpq.br/estatisticas/TabelasdeQuantitativos/21_TotalBolsas_5108_n_v2.xls

Crubellate, J. M. (2007). Três contribuições conceituais neofuncionalistas à teoria institucional em organizações. Revista de Administração Contemporânea, 11(1ª Edição Especial), 199-222.

Crubellate, J. M., Grave, P. S., \& Mendes, A. A. (2004). A questão institucional e suas implicações para o pensamento estratégico. Revista de Administração Contemporânea, 8(3), 37-60.

Crubellate, J. M., Rossoni, L., Mello, C. M., \& Valenzuela, J. E. B. (2008). Respostas estratégicas de programas paranaenses de mestrado/doutorado em administração à avaliação da CAPES: configurando proposições institucionais a partir de redes de cooperação Acadêmica. Revista de Negócios, 13(2), 77-92.

Dacin, M. T., Oliver, C., \& Roy, J. (2007). The legitimacy of strategic alliances: an institutional perspective. Strategic Management Journal, 28(2), 169-187.

DiMaggio, P., \& Powell, W. (1991). The iron cage revisited: institutional isomorphism and collective rationality. In W. Powell \& P. DiMaggio (Eds.), The new institutionalism in organizational analysis (pp. 63-82). Chicago: The University of Chicago Press.

Garud, R., Hardy, C., \& Maguire, S. (2007). Institutional entrepreneurship as embedded agency: an introduction to the special issue. Organization Studies, 28(7), 957-969.

GeoCapes Dados Estatísticos. (2009). Concessão de bolsas de pós-graduação da Capes no Brasil. Recuperado em 28 abril, 2010, de http://geocapes.capes.gov.br/geocapesds/\#app=3099\&da7aselectedIndex $=0 \& 5317$-selectedIndex $=0 \&$ c0ef-selectedIndex $=0$

Granovetter, M. S. (1973). The strength of weak ties. American Journal of Sociology, 78(6) 1361-1380. 
Hanneman, R. A., \& Riddle, M. (2005). Introduction to social network methods. Riverside: University of Califórnia.

Hardy, C., \& Clegg, S. R. (2001). Alguns ousam chamá-lo de poder. In M. Caldas, R. Fachin, \& T. Fischer (Orgs.), Handbook de estudos organizacionais (Vol. 2). São Paulo: Atlas.

Hatch, M. J. (1997). Organization theory: modern, symbolic and postmodern perspectives. Oxford: Oxford University Press.

Machado-da-Silva, C. L. (2003). Respostas estratégicas da administração e contabilidade ao sistema de avaliação da Capes. Revista Organização e Sociedade, 10(28), 63-77.

Machado-da-Silva, C. L., Fonseca, V., \& Crubellate, J. M. (2005). Estrutura, agência e interpretação: elementos para uma abordagem recursiva do processo de institucionalização. Revista de Administração Contemporânea, 9(1ª Edição Especial), 9-40.

Meyer, J. W., \& Rowan, B. (1977). Institutionalized organizations: formal structure as myth and ceremony. American Sociological Review, 83(2), 340-363.

Moody, J. (2004). The structure of a social science collaboration network: disciplinary cohesion from 1963 to 1999. American Sociological Review, 69(2), 213-238.

Nicolato, M. A. (2005). Sinopse da avaliação trienal da pós-graduação-2004 (período avaliado: 20012003). Revista Brasileira de Pós-graduação, 2(3), 176-184.

Nooy, W. de, Mrvar, A., \& Batagelj, V. (2005). Exploratory social network analysis with Pajek. New York: Cambridge University Press.

Oliver, C. (1991). Strategic responses to institutional processes. Academy of Management Review, 16(1), 145-179.

Rodan, S., \& Galunic, C. (2004). More than network structure: how knowledge heterogeneity influences managerial performance and innovativeness. Strategic Management Journal, 25(6), 541-562.

Rossetto, C. R., \& Rossetto, A. M. (2005). Teoria institucional e dependência de recursos na adaptação organizacional: uma visão complementar. RAE-Eletrônica, 4(1), 1-22. Recuperado em 10 outubro, 2007, de http://www16.fgv.br/rae/artigos/1869.pdf

Rossoni, L. (2006). A dinâmica de relações no campo da pesquisa em organizações e estratégia no Brasil: uma análise institucional. Dissertação de mestrado, Universidade Federal do Paraná, Curitiba, PR, Brasil.

Rossoni, L., \& Guarido Filho, E. R. (2007). Cooperação interinstitucional no campo da pesquisa em estratégia. Revista de Administração de Empresas, 47(4), 72-86.

Rossoni, L., \& Guarido Filho, E. R. (2009). Cooperação entre programas de pós-graduação em administração no Brasil: evidências estruturais em quatro áreas temáticas. Revista de Administração Contemporânea, 13(3), 366-390.

Rossoni, L., \& Hocayen-da-Silva, A. J. (2008). Cooperação entre pesquisadores da área de administração da informação: evidências estruturais de fragmentação das relações no campo científico. Revista de Administração, 43(2), 138-151.

Rossoni, L., Hocayen-da-Silva, J., \& Ferreira, I., Jr. (2008). Aspectos estruturais da cooperação entre pesquisadores no campo da administração pública e gestão social: análise das redes entre instituições no Brasil. Revista de Administração Pública, 47(6), 1041-1067 
Rowan, B. (2006). The new institutionalism and the study of educational organizations: changing ideas for changing times. In $\mathrm{H}$. Meyer \& $\mathrm{B}$. Rowan (Eds.), The new institutionalism in education. (pp. 15-32). Albany: State University of New York Press.

Scott, W. R. (2001). Institutions and Organizations (2a ed.). Thousand Oaks: Sage.

Selltiz, C., Jahoda, M., Deutsch, M., \& Cook, S. W. (1975). Métodos de pesquisa nas relações sociais. São Paulo: EPU.

Wasserman, S., \& Faust, K. (1994). Social network analysis: methods and applications. Cambridge: Cambridge University Press.

Watts, D. J., \& Strogatz, S. W. (1998, June 4). Collective dynamics of "small-world" networks. Nature, 393, 440-442. 